\section{Análise das Políticas Educacionais na Oferta de Educação Infantil na Região Metropolitana de Curitiba e Litoral do Paraná}

Ângelo Ricardo de Souza' Alexandra Ferrari Damaso ${ }^{2}$

Resumo:

Este estudo compõe parte de pesquisa conduzida pelo Núcleo de Políticas, Gestão Financiamento da Educação da UFPR e objetiva valiar os impactos das políticas educacionais na educação infantil, no período entre 2001 e 2006 Desde a constituição de 1988, o atendimento de crianças em creches e pré-escolas foi incluído entre os direitos à educação básica, retirando o atendimento à criança do campo assistencia reconhecendo-o como parte do sistema educacional, o que demonstra um grande avanço político ao ter um olhar voltado para a ducação da primeira infância. Com esta nova organização, há a necessidade da avaliação dos impactos destas ações no campo da ducação infantil e a busca da relação oferta cobertura e qualidade da educação contribu a este fim. Em conjunto com a pesquisa do núcleo, através de bancos de dados do INEP, PARDES e IBGE, traçou-se um panorama da etapa na região metropolitana de Curitiba Litoral paranaense - RMCL. Na região houve um aumento no número de estabelecimentos que atendem à educação infantil, nas suas duas etapas (creche e pré-escola), refletindo no aumento de matrículas, apesar do crescimento demográfico para esta faixa etária apresenta resultado negativo. O percentual de crescimento dos estabelecimentos escolares de educação infantil para este período é de $22 \%$ na creche $13 \%$ na pré-escola, aumentando a oferta de matrículas em $17,5 \%$ e $47,5 \%$ respectivamente. A rede de educação infantil cobre $22,5 \%$ da população infantil nesta faixa etária, sendo que a rede pública atende $15,2 \%$. As conclusões do estudo apontam que, apesar da insuficiente cobertura, uma vez que menos de três de cada dez crianças com seis anos de idade ou menos estão sendo atendidas, houve crescimento das matrículas no período, sugerindo que o poder público, apesar de estar reagindo à pressão cobrança sociais na ampliação do atendimento desta etapa da educação básica, o faz de forma pouco articulada e organizada regionalmente e mesmo localmente, demonstrando que o crescimento é ainda insuficiente.
Palavras-chave: Educação Infantil; Políticas Educacionais; Região Metropolitana.

\section{Introdução}

Há uma questão importante que se faz inicial quando da discussão sobre as políticas de educação infantil. Este debate versa sobre as idéias de demanda social e justiça social. A compreensão que este trabalho tem de demanda socia pela educação infantil se articula com o reconhecimento da necessidade e/ou direito das crianças de 0 a 6 anos e de seus familiares no atendimento educaciona público de qualidade, independente desta demanda ser explícita ou latente ${ }^{3}$.

A análise das políticas educacionais exige, quando o foco é um determinado período ou modalidade não-obrigatória da educação, o cotejamento entre as diferentes demandas. Os dados de crescimento de matrículas não podem ser dissociados, de um lado, das possibilidades de atendimento e, de outro, das necessidades da população em relaçãoàquele bem ou serviço. Ademais, - possível reconhecimento do poder público como efetivo no atendimento ao interesse educacional público depende do cotejamento entre quantidade e qualidade de oferta educacional, entre demandas explícitas e demandas latentes.

A associação entre demanda latente e qualidade educacional aqui sugerida se explica pela constatação empírica de que parte da população que precisa de serviços educacionais em etapas não obrigatórias da educação básica, não procura a rede pública porque não vê significância no resultado do trabalho desenvolvido pelo poder público, isto é, avalia tal resultado como de baixa qualidade e, assim sendo, prefere não se socorrer deste serviço. Isto não quer dizer que se trate de pessoas que não precisam de oferta de educação infantil. Ao contrário, a demanda neste caso não é explícita, porque a demanda existente é menos pela vaga em si, e mais pela qualidade do serviço ofertado

Neste sentido, a avaliação da política de educação infantil não pode se reduzir à análise da oferta educacional condicionada ao princípio amplo do direito "a cada um de acordo com o que the é devido", uma vez que

3“(...) Ela pode ser explícita ou latente: a explícita é avaliada através da procura de um serviço. A demanda (T) ${ }^{4}$ Esta questão precisa ser melhor investigada, mas há estudos que demonstram uma avaliação crítica dos familiares dos alunos em relação à qualidade na educação infantil. 
que é devido a cada sujeito na sociedade é algo bastante amplo e vago. Énecessária uma definição mais objetivada sobre um princípio de justiça social consistente e coerente (FIGUEIREDO, 1997) ${ }^{5}$, pois o que está em questão é o atendimento educacional às crianças de 0 a 6 anos com toda a qualidade. Se o limite da avaliação das políticas educacionais se resume à necessidad de atendimento, portanto se restringindo a uma perspectiva de quantidade, temos de dimensionar o que é a necessidade de cada cidadão. A necessidade é aquilo que cuja falta provoca um dano (FIGUEIREDO, 1997)? Neste caso, é possível concluir que sim, pois a não oferta de educação básica provoca dano do não atendimento àquelas pessoas em um nível de ensino que, embora não obrigatório em sua plenitude, é essencial ${ }^{6}$.

Isto quer dizer que a discussão sobre demanda latente e sobre qualidade na educação infantil é ainda mais complexa uma vez que, como veremos adiante, nem a mais preliminar das condições de qualidade, que é a quantidade de vagas disponíveis para a cobertura educacional, está dada.

Destarte, nos marcos deste estudo, mesmo sabendo da importância de se definir melhor os critérios de qualidade educacional, compreendemos que a garantia de vagas para a universalização do acesso à educação infantil é um importante critério de justiça social e, como tal, será utilizado para se dimensionar a efetividade da política educacional nos municípios da Região Metropolitana de Curitiba e Litora do Paraná (RMCL).
Historicamente, a educação infantil foi mantida e desenvolvida até pouco tempo atrás pela assistência social, pois a ação do poder público para as crianças de 0 a 6 anos de idade só foi reconhecida publicamente como educação formal há poucos anos. Esta constituição histórica desta etapa da educação básica é, em parte, responsável pela dissociação entre oferta de educação infantil e dever público, pois o senso comum tende a compreender esta oferta como um plus ofertado pelos diferentes governantes, dada a ausência de reconhecimento dos direitos sociais pela própria população.

0 campo apresenta ainda uma grande complexidade conceitual, um desencontro entre as diretivas institucionais, legais e prática cotidiana cristalizadas através de uma história política de irmão caçula e pobre do sistema educacional brasileiro: caçula porque a creche recém entrou na legislação nacional brasileira; pobre porque em decorrência dos recursos que Ihe vêm sendo alocados, de sua vinculação estreita com a assistência social, e por isso, no Brasil, sinônimo de serviço destinado a usuário pobre (Rosemberg, 1999, p.5).

Os dados a seguir demonstram que é significativa a falta de prioridade para com a educação infantil. Ainda que seja possível observar crescimento na ofertaeducacional ela é absolutamente insuficiente para o atendimento da população infantil. A hipótese central que este trabalho toma na busca das razões para tal comportamento aponta para a oferta de educação infantil nos municípios da região predominantemente condicionada à pressão popular. Não parece haver uma política de educação infantil que considere as demandas explícitas que não se organizam, dadas aquelas características da constituição histórica desta etapa educacional.

\section{Metodologia e Caracterização da RMCL}

Esta investigação foi desenvolvida na Região Metropolitana de Curitiba e Litora do Paraná (RMCL), que é constituída por 33 municípios. Trabalhamos com dados de matrícula na educação infantil e população de crianças de 0 a 6 anos advindos de fontes indiretas, recolhidos nos seguintes bancos de dados: Instituto Nacional de Estudos e Pesquisas Educacionais Anísio Teixeira - INEP (www.inep.gov.br); Instituto Brasileiro de Geografia e Estatística - IBGE (www.ibge.gov.br) e Instituto Paranaense de Desenvolvimento Econômico e Social - IPARDES (www.ipardes.gov.br)

A análise parte da observação do movimento das matrículas no período entre 2001 e 2006. A definição deste prazo articulase com o desenvolvimento da "pesquisamãe" donde este estudo é derivado?

Os dados de matrículas foram cotejados com os dados populacionais da região. Esta variável emerge das análises desenvolvidas pelos institutos citados partir dos dados do censo populaciona de 2000 e das pesquisas nacionais por amostra de domicílios (PNAD) realizadas nos anos subseqüentes. As informações da coorte etária são projetadas por município com base em curvas históricas de alteração do quantitativo populacional e permitem as inferências aqui desenhadas.

$\mathrm{O}$ que levou o estudo a pesquisar Região Metropolitana de Curitiba e Litora do Paraná (RMCL) foi a necessidade de entrecruzar as políticas oriundas de diferentes administrações, dado que na região as fronteiras territoriais, base para definição do campo de atuação das respectivas administrações e suas políticas são diluídas pelo movimento populacional.

0 crescimento das cidades e, principalmente, de pólos centrais de desenvolvimento econômico, margeadas por áreas de forte concentração urbana periférica, implicam desafios para democratização de direitos sociais básicos, posto que há áreas de interseccão para as quais o formato da administração pública ainda não desenvolveu mecanismos de enfrentamento do problema (GOUVEIA \& SOUZA, 2005).

A insuficiente articulação entre os municípios da RMCL expressa também a desarticulação do pretendido regime de colaboraçãoentreosentesfederativos (união, estados e municípios), particularmente nesta etapa da educação, uma vez que sua responsabilidade é, conforme a legislação, exclusivamente municipal. Os municípios têm de ofertar a educação infantil e até pouco tempo não havia nenhum mecanismo de (re)distribuição financeira que auxiliasse queles mais pobres na condução desta tarefa, para além do investimento obrigatório definido constitucionalmente. Isto é, as condições dos municípios (mesmo vizinhos) 
são bastante diversas, especialmente no que tange às condições de financiamento das políticas sociais e, ainda mais particularmente nas regiões metropolitanas (GOUVEIA \& SOUZA, 2005); e a existência de algum esforço de articulação e de planejamento das políticas sociais que supere as fronteiras municipais parecia existir, na educação, somente no âmbito do ensino fundamental. A soma desses elementos compõe um quadro denunciador da aparente ausência de responsabilidades do estado e da união na coordenação de uma política de educação infantil, em particular nessas regiões, como a RMCL, na qual a mobilidade populacional e o conseqüente trânsito de demandas sociais são intensos.

Estimativas do IBGE apontam que a RMCL tem 3.880.000 habitantes concentrando o maior PIB do sul e o terceiro maior do país. O PIB per capita na região era, em 2002, da ordem de $\mathrm{R} \$$ $9.676,00$, porém com variações muito grandes entre os municípios (de R\$ 2.925,00, em Itaperuçu a $\mathrm{R} \$ 44.477,00$, em Araucária).

O IDHM da região era em 2000 de 0,824 mas com municípios que apresentavam índices muito baixos, como os localizados no Vale do Ribeira que apresentam os piores indicadores do estado inteiro e de outra parte, com outros municípios com índices dentre os mais elevados do estado, também evidenciando as grandes desigualdades internas à região. O IDHM-Educação também apresenta variação na região $(0,695$, em Tunas do Paraná a 0,946, em Curitiba, tendo como média na região 0,911), demonstrando que os municípios mais autônomos financeiramente apresentam melhores condições de implementação das políticas sociais/educacionais.
2. As políticas de educação infantil na RMCL

O estudo mapeia a rede educacional da Região Metropolitana de Curitiba Litoral - RMCL, na coorte da educação infantil - 0 a 6 anos, durante o período de 2001/2006, através do acompanhamento do crescimento populacional, oferta de matrículas e número de estabelecimentos educacionais para esta faixa etária.

De acordo com os dados, os estabelecimentos de educação infantil cresceram $16 \%$ na RMCL, acompanhando o crescimento do estado que em sua totalidade apresentou uma taxa positiva de $15,7 \%$. Na RMCL, a rede pública é responsável por um crescimento de 17,9\% para o período. Enquanto que para este período o crescimento populacional do Paraná da faixa etária em questão (0 a 6 anos) apresentou índice negativo de 11,3\% e na região de $-2,7 \%$.

Gráfico 1: Crescimento da Oferta de Estabelecimentos de Educação Infantil $-2001 / 2006$

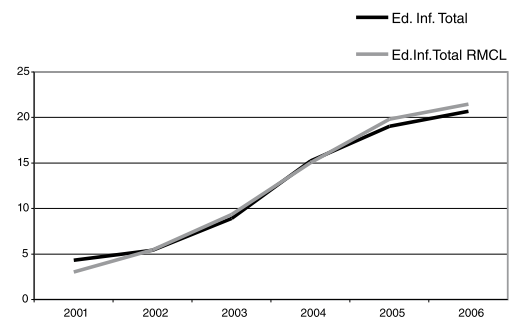

Este aumento no número de estabelecimentos acarretou uma ampliação na oferta de matrículas em $23 \%$ e, em relação à cobertura, parte-se em 2001 de $19,9 \%$ para $24,6 \%$ em 2006. O que demonstra que o planejamento para esta modalidade apresenta valores muito abaixo da demanda, pois nesta coorte etária a maioria não é atendida seja na rede pública, seja na rede privada. Convém ressalta que para este período o crescimento populacional que comporta esta faixa etária foi negativo na ordem de 2,7\%. Na rede pública temos um aumento de cobertura de 18,6\% em 2001 para 26,0\% em 2006. Em 2001, a rede pública atendia 55.147 crianças o que correspondia a 11,3\% da população infantil desta faixa etária e a rede privada 31.746 crianças que equivale a $7,2 \%$. Até 2006, houve um aumento de cobertura na rede pública resultando em $15,2 \%$ que corresponde a 72.642 crianças, enquanto na rede privada o a cobertura continuou a ser de $7,2 \%$, atendendo a 34.364 crianças.

Gráfico 2: Cobertura na Educação Infantil na RMCL - 2006

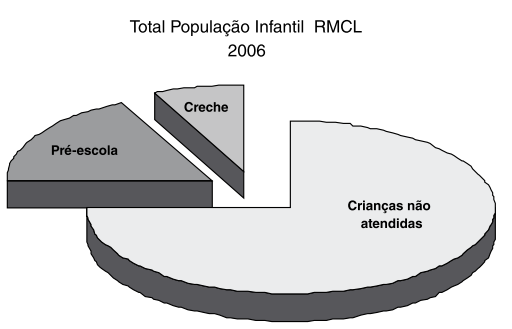

No atendimento à primeira etapa - 0 a 3 anos, houve um crescimento de 25,9\% no número de estabelecimentos, ampliando a cobertura de 9,4\% em 2001 para $12,1 \%$ em 2006. Para este período houve um decréscimo populacional nessa faixa etária de 8,6\%. Com o crescimento populacional negativo, a ampliação na oferta de matrículas torna-se mais significativa, pois o aumento provoca dupla ampliação da cobertura: pelo aumento das matrículas e pela diminuição da demanda potencial. Porém, mesmo com o crescimento a cobertura é aind abaixo da demanda populacional, sendo que a rede pública contemplava apenas $8,2 \%$ da população infantil desta faixa e a privada $3,8 \%$, no ano de 2006

Para 0 atendimento das crianças de 4 a 6 anos, a taxa de crescimento do número de estabelecimentos foi de $11,2 \%$. Nesta etapa, a rede municipa apresentou crescimento superior à rede privada (14,3\% na rede pública contra $7.6 \%$ na rede privada). Em 2006, a rede pública atendeu a 51.514 crianças e rede privada 24.542 crianças. Apesa de proporcionalmente a ampliação do número de escolas ser menor em relação à faixa etária de 0 a 3 anos, houve aumento maior nas matrículas, as quais atingiram $25,9 \%$, sendo que a rede pública apresentou um acréscimo de $47,5 \%$ e a rede privada de 5,3\%. Em contrapartida, ocrescimento populaciona para esta faixa etária apresenta-se mais estável que para a faixa anterior. A pré-escola parece compor mesmo parte das políticas de educação básica no âmbito dos municípios da região especialmente porque se trata de uma etapa da educação menos onerosa financeiramente que a etapa anterior, em particular com a ampliação da oferta, em parte considerável dos casos, em escolas/turmas com regime de 4 horas diárias, contra as 8 ou mais horas costumeiras na oferta da creche.

Fazendo uma projeção considerando constante a taxa de crescimento da oferta de matrículas ocorrida neste período (2001-2006), que foi da ordem de $23 \%$ para a educação infantil, como vimos, somente a partir de 2051 teremos a oferta compatível com a população infantil. 
Próximo a 2028, a oferta de matrículas da pré-escola será suficiente para atender a demanda populacional de 4 a 6 anos. No entanto, para a creche o quadro é muito mais complexo, pois, em se mantendo os índices, a universalização da oferta para esta etapa só ocorrerá na RMCL, a partir de 2110: um século adiante!

É importante se destacar que essa projeção não se efetivará desta forma, pois as taxas de crescimento populacional e de matrículas encontradas e/ou projetadas não se manterão estáveis, uma vez que há diversas outras variáveis não consideradas. A principal delas, no que concerne à política educacional é a implantação do Fundo de Manutenção e Desenvolvimento da Educação Básica - FUNDEB, que inclui as matrículas de creche e pré-escola progressivamente nos próximos anos para efeitos de recebimento de recursos financeiros. É verdade que os impactos possíveis com o advento do Fundo serão os mais variados nos distintos municípios, dadas as realidades locais diversas, como destacado. Contudo, fato dos municípios receberem recursos por alunos matriculados na educação infantil, de um lado, e a possibilidade de contabilizar as matrículas na rede conveniada, por outro, podem servir de incentivo para a ampliação da oferta, mesmo que pela rede privada/ conveniada. Ademais, a universalização do ensino fundamental e a ampliação do atendimento ao direito educacional nas diversas etapas da educação básica, somadas à pressão popular podem provocar os administradores públicos a ampliar a oferta da educação infantil.

De outro lado, a taxa de natalidade tende a decrescer, ainda que em regiões metropolitanas o crescimento populacional seja, em grande parte derivado de processos migratórios. A queda daquela taxa também potencializa a diminuição da demanda e a ampliação da cobertura. De qualquer forma, o intuito de destacar aqui aquela projeção reside na tentativa de demonstrar a insuficiência do atendimento educacional na etapa da educação infantil.

Convém ressaltar que para critérios de projeção estatística, foram desconsiderados fatores importantes ao tomar a demanda como critério único. Para um efetivo planejamento, há fatores relevantes como qualidade dos serviços prestados, localização das escolas, creches e centros de educação infantil, as necessidades específicas dos familiares (para além da criança) horários ofertados, dentre outras. Apesar do público atendido pela educação infantil ser composto por crianças é principalmente aos pais, mães efamiliares que essas ações devem se direcionar, já que para esta faixa, a criança inserida na escola possibilita condições adequadas de atendimento e formação, bem como o retorno/ida ao mercado de trabalho das mães, principalmente àquelas da primeira faixa etária (0 a 3 anos).

Gráfico3:Projeção paraauniversalização do acesso à creche - RMCL

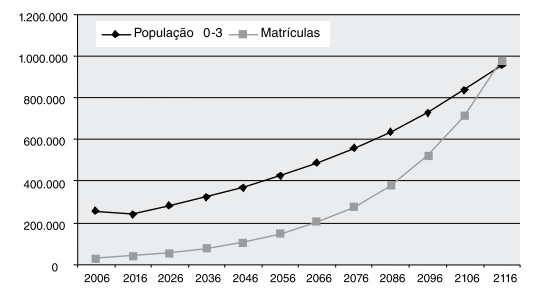

Gráfico 4:Projeçãoparaauniversalização da pré-escola - RMCL

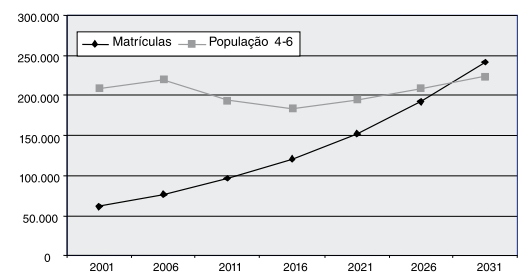

Tabela 1: Projeção de oferta de vagas na Educação Infantil - 2006/2041

\begin{tabular}{|c|c|c|c|}
\hline População & $\begin{array}{c}\text { Sub-total } \\
0-3 \text { anos }\end{array}$ & $\begin{array}{c}\text { Sub-total } \\
4-6 \text { anos }\end{array}$ & TOTAL \\
\hline 2006 & 256.680 & 219.866 & 476.546 \\
\hline 2011 & 232.080 & 193.998 & 426.078 \\
\hline 2021 & 264.359 & 195.404 & 459.628 \\
\hline 2031 & 302.665 & 223.718 & 526.228 \\
\hline 2056 & 424.503 & 313.776 & 738.062 \\
\hline 2076 & 556.437 & 411.296 & 967.449 \\
\hline 2096 & 729.375 & 539.126 & 1.268 .128 \\
\hline 2116 & 956.062 & 706.684 & 1.662 .257 \\
\hline
\end{tabular}

Obs. taxa de crescimento utilizada para a projeção de $23 \%$ a cada 5 anos (indice verificado entre 2001 e 2006) Fonte: Banco de dados da Pesquisa

Tabela 2: Matrículas Educação Infanti 2001/2006

\begin{tabular}{|c|c|c|c|}
\hline Ano & Creche & Pré-escola & Total \\
\hline 2001 & 26.444 & 60.455 & 86.899 \\
\hline 2002 & 26.760 & 59.045 & 85.805 \\
\hline 2003 & 29.027 & 65.300 & 94.327 \\
\hline 2004 & 29.148 & 70.037 & 99.185 \\
\hline 2005 & 31.301 & 72.049 & 103.350 \\
\hline 2006 & 30.950 & 76.116 & 107.066 \\
\hline Crescimento & 17,0 & 25,9 & 23,2 \\
\hline \multicolumn{4}{|c|}{ Fonte: MEC-INEP } \\
\hline
\end{tabular}

(www.inep.gov.br, acessado em outubro de 2007).

Não parece haver estudos que estimem adequadamente este tipo de demanda, ainda que um bom levantamento das listas de espera nos centros de educaçãa infantil pudessem dar conta. Ainda assim, educadores e
sindicatos, em alguns locais (como Curitiba), afirmam que para cada criança matriculada em uma escola infantil, há outra na lista de espera.

\section{Considerações finais}

O crescimento da oferta da educação infantil na RMCL é evidente, mas insuficiente, ainda que tenhamos de considerar que as curvas de crescimento projetadas anteriormente não se efetivarão da forma desenhada, pois tanto os possíveis impactos do FUNDEB, quanto as alterações nas taxas de natalidade e migração populacional seguramente reduzirão o prazo para a universalização do acesso. Essas possíveis alterações na projeção dos dados, então, não podem obstar a constatação da complexidade que a situação atual e projetivamente futura apresentam. A demanda explícita grande ${ }^{8}$. A demanda latente é incalculável, porque exige uma avaliação sobre a percepção dos cidadãos em relação aos erviços educacionais públicos em geral sobre a qualidade da educação infantil em especial. Neste sentido, podemos concluir que $\mathrm{o}$ atendimento à educação infantil na RMCL não é adequado às necessidades sociais

Com este quadro, a extensão da justiça social é prejudicada, uma vez que aquelas necessidades são, potencialmente, de todos/as que têm filhos, contudo, são as familias mais carentes economicamente as mais prejudicadas, dado que é esta camada da população que prioritariamente se vale dos serviços públicos de educação infantil e se a universalização do acesso tardará tanto quanto projetamos, sãoessas pessoas, á excluídas de diversos direitos sociais, as que mais sofrerão. Se a necessidade se 
avalia pelo dano que a falta do atendimento gera e aquelas pessoas que se socorrem dos serviços públicos educacionais não têm outras alternativas para tal atendimento e, ainda, se as possibilidades de alteração/ passam necessariamente pelo incremento do nível educacional, ora, então há sentida injustiça social nas políticas de educação infantil na RMCL.

\section{Bibliografia}

FIGUEIREDO, A. Princípios de justiça e avaliação de políticas. Lua Nova. Revista de Cultura e Política. 1997, n³9, CEDEC

GOUVEIA, A. \& SOUZA, A. O financiamento da educação em municípios da região metropolitana de Curitiba/PR/Brasil: os desafios frente à expansão da oferta numa região em crescimento. Scripta Nova: Revista electrónica de geografía y ciencias sociales. 2005.

Vol. 9: Los agentes urbanos y las políticas sobre la ciudad. Número extraordinario dedicado al VII Coloquio Internacional de Geocrítica (Actas del Coloquio). Barcelona. Disponível em http:// www.ub.es/geocrit/sn/sn-194-64.htm.

Instituto Nacional de Estudos e Pesquisas Educacionais Anísio Teixeira - INEP (www.inep.gov.br). Instituto Brasileiro de Geografia e Estatística - IBGE (www.ibge.gov.br).

Instituto Paranaense de Desenvolvimento Econômico e Social - IPARDES (www.ipardes.gov.br).

ROSEMBERG, F. Expansão da Educação Infantil e Processos de Exclusão. Cadernos de Pesquisa, n. 107, p.7-40, julho/1999.

O estado dos dados para avaliar políticas de educação Infantil.

Estudos em Avaliação Educacional. n² 20, jul-dez/1999.

Recebido em agosto de 2007

Aprovado em setembro de 2007

RESENHA

\section{SANDER, BENNO. Administração da Educação no Brasil: Genealogia do Conhecimento. Brasília: Liber Livro, 2007.}

Por Luiza Freire Noguchi

O campo da Administração Escolar ou Gestão Escolar, como é abordado na atualidade, teve diversos estudos sistemáticos de educadores brasileiros, no decorrer do século $\mathrm{XX}$, na tentativa de elaborar conceitos teóricos e dar-Ihe significado. Estes estudos se deram pela necessidade emergencial de organização técnica, pedagógica e administrativa nas ações das organizações escolares.

São identificáveis três momentos históricos de reflexões sobre a práxis neste campo: um primeiro momento (início do século XX até meados dos anos 70) é o de sistematização do conhecimento acerca do campo de caráter mais técnico e pragmático; um segundo momento de crítica aos modelos das décadas anteriores que se inicia concomitante aos movimentos de redemocratização política dos anos 80 e finalmente o atual momento, de novas configurações para o campo sob o signo de gestão, a partir da década de 90 e à luz das novas configurações do capitalismo em âmbito mundial.

É no contexto de crítica aos modelos anteriores, iniciado em meados dos anos 80, que Benno Sander lança em 1982 a primeira versão de Administração da Educação no Brasil: Genealogia do
Conhecimento, entretanto após diversas publicações, agregou outras reflexões $e$ apontamentos sobre o tema e relançou obra em 2007, com a coerente justificativa "de que aquilo que sabíamos ontem já não é suficiente hoje" (SANDER, 2007, p.7).

O objetivo do autor é ensaiar sobre o que ele denomina "paradigma multidimensional da administração da educação" (idem, p.9), ou seja, dimensionar as várias faces que compõe o conceito e a prática da administração escolar. Sendo assim, o autor estruturou sua obra em três capítulos: no primeiro detém-se na introdução à genealogia do conhecimento da administração escolar ao longo da história brasileira; no segundo capítulo constró de maneira extremamente didática quatro modelos de gestão da educação, à luz da história analisada no capítulo anterior e finalmente no terceiro capítulo ensaia "uma perspectiva analítica e praxiológica de gestão educacional" (SANDER, 2007, p.8) com o objetivo de dimensionar e conceituar o paradigma anteriormente citado.

Para o autor só é possível a compreensão do campo da administração escolar, tendo em vista que "a gestão da educação, longe de ser um instrumento ideologicamente neutro, desempenha um papel político e cultural 